\title{
Tailoring a ConOps for NASA LSP Integrated Operations
}

\author{
"Skip" Clark V. Owens III \\ NASA-LSP Kennedy Space Center \\ Mail Code: VA-G2 \\ Kennedy Space Center, FL 32899 \\ $1+321-867-293$ \\ skip.owens-1@NASA.gov \\ Published and used by INCOSE with permission.
}

\begin{abstract}
An integral part of the Systems Engineering process is the creation of a Concept of Operations (ConOps) for a given system, with the ConOps initially established early in the system design process and evolved as the system definition and design matures. As Integration Engineers in NASA's Launch Services Program (LSP) at Kennedy Space Center (KSC), our job is to manage the interface requirements for all the robotic space missions that come to our Program for a Launch Service. LSP procures and manages a launch service from one of our many commercial Launch Vehicle Contractors (LVCs) and these commercial companies are then responsible for developing the Interface Control Document (ICD), the verification of the requirements in that document, and all the services pertaining to integrating the spacecraft and launching it into orbit. However, one of the systems engineering tools that have not been employed within LSP to date is a Concept of Operations. The goal of this paper is to research the format and content that goes into these various aerospace industry ConOps and tailor the format and content into template form, so the template may be used as an engineering tool for spacecraft integration with future LSP procured launch services. This tailoring effort was performed as the author's final Masters Project in the Spring of 2016 for the Stevens Institute of Technology and modified for publication with INCOSE (Owens, 2016).
\end{abstract}

\section{Examination of a Concept of Operations}

\section{Terminology}

The first step in tailoring an established standard or body of work for a specific task is to completely understand the original intent of that material. What is a Concept of Operations? The first recorded use of a ConOps document was in the paper by R.J. Lano, "A Structured Approach for Operational Concept Formulation" TRW SS-80-002, TRW Defense and Space Systems Group in 1980 (IEEE, 2007). With over 36 years of ConOps history under our collective belts it would only be logical to conclude that the term ConOps has a very universally accepted meaning. However, if you ask systems engineers today for a definition of a ConOps you will get a wide variety of responses, with each individual answer heavily slanted toward the type of work or systems with which each particular systems engineer is working. Sometimes a single diagram will be referred to as a ConOps and other times a rather lengthy and detailed document. NASA's Lifecycle, Processes and Systems Engineering course (APPEL-LPSE, 2011) describes an Operations Concept as having a variety of common names at each level: 
At the System Level:

- Concept of Operations (CONOPS) Document

- Operational Concept Document

- Context of Operations Statement

At the Configuration Level:

- User's Manual

- Operator's Manual

At the Component Level:

- Design Description

There are many "official" definitions of a Concept of Operations, so this paper will start by acknowledging these definitions and will then establish a working definition for the specific ConOps that is being tailored for the Launch Services Program.

There are two main terms that are associated with a Concept of Operations that are often used interchangeably:

- Concept of Operations (ConOps)

- Operational Concept (OpsCon)

In reality, these two terms have very different meanings and these two distinct meanings from ISO/EEC/IEEE 29148 referenced below are used consistently by ANSI/AIAA, ISO/DEC/IEEE, and the Department of Defense (as cited in Walden, 2015).

ConOps description according to the INCOSE Systems Engineering Handbook Version 4 (as cited in Walden, 2015):

"The ConOps, at the organization level, addresses the leadership's intended way of operating the organization. It may refer to the use of one or more systems, as black boxes, to forward the organization's goals and objectives. The ConOps document describes the organization's assumptions or intent in regard to an overall operation or series of operations of the business with using the system to be developed, existing systems, and possible future systems. This document is frequently embodied in long-range strategic plans and annual operational plans. The ConOps document serves as a basis for the organization to direct the overall characteristics of the future business and systems, for the project to understand its background, and for the users of ISO/EEC/IEEE 29148 to implement the stakeholder requirements elicitation."

Operational Concept (OpsCon) description according to the INCOSE Systems Engineering Handbook Version 4 (as cited in Walden, 2015):

"A System Operational Concept (OpsCon) document describes what the system will do (not how it will do it) and why (rationale). An OpsCon is a user-oriented document that describes system characteristics of the to-be-delivered system from the user's viewpoint. The OpsCon document is used to communicate overall quantitative and qualitative system characteristics to the acquirer, user, supplier and other organizational elements."

From these two established and rather well accepted definitions the following conclusions can be made. The ConOps is more focused on the operational aspects of the system in question, 
while the OpsCon is a higher-level document that is focused more on general function (what the system will do) in the terms of the end user. Since the purpose of tailoring a Concept of Operations for use by NASA's Launch Services Program is operationally focused and will be used to convey the technical operations of integrating a spacecraft with the launch vehicle, the formal definition above for a ConOps is a better fit. From this point forward in the paper the terms Concept of Operations and ConOps will be used interchangeably and will generally refer to the above INCOSE cited definition of a ConOps.

\section{Defining a Concept of Operations}

Now that the general terminology associated with the term ConOps has been established for this paper, the next step is to go into a more thorough definition for a ConOps. A Concept of Operations can have many uses and can therefore have a wide variety of meanings. The first example to consider is the definition by the Department of Defense from the Dictionary of Military and Associated Terms ("DOD Dictionary of Military and Associated Terms", 2002):

"A verbal or graphic statement that clearly and concisely expresses what the joint force commander intends to accomplish and how it will be done using available resources. The concept is designed to give an overall picture of the operation. Also called commander's concept or CONOPS."

The "Applied Space Systems Engineering" book (Larson, 2009) is another good source for a concise definition of a Concept of Operations:

"A good concept of operations verbally and graphically reflects stakeholders' expectations, so it becomes a platform for validating the system's architecture and technical requirements."

Notice that both definitions use the terms "verbal" and "graphic", meaning that a ConOps should use both words and pictures to convey the content to the audience. The Applied Space Systems Engineering definition also goes on to say that a ConOps is a "platform for validating the system's architecture and technical requirements." As systems engineers, we are relatively good at writing requirements and these requirements almost always end up in a dedicated requirements document. This requirements document is all too often devoid, or at best, sparsely populated with figures and diagrams. Requirements documents are meant to be very specific, so it is left up to the ConOps to paint the high-level or "overall picture of the operation" to which the DOD definition refers. The DOD and Applied Space Systems Engineering definitions very clearly establish the following attributes for a ConOps:

- Verbal and graphical

- Overall picture of the operations

- A platform for validating the system's architecture and technical requirements

- A concise expression of what must be accomplished by the system

The Applied Space Systems Engineering book also cites the following as the purpose behind establishing a ConOps (as cited in Larson, 2009):

- Describe the system's operational characteristics

- Help users, customers, implementers, architects, testers, and managers understand system goals

- Form a basis for long-range operations planning 
- Guide how system definition documents, such as system and interface specifications, develop

- Describe how the user's organization and mission relate to the system

The final professional source that should be considered for establishing a vision for what a tailored LSP ConOps should entail is the NASA Systems Engineering Handbook. The definition that NASA uses in the handbook is very similar to definitions referenced above, but the handbook provides some additional characteristics that are worth consideration (NASA Systems Engineering Handbook, 2007):

"The ConOps is an important driver in the system re $\neg q u i r e m e n t s$ and therefore must be considered early in the system design processes. Thinking through the ConOps and use cases often reveals requirements and design functions that might otherwise be overlooked."

The key attributes from the NASA Systems Engineering Handbook for the LSP ConOps are the following:

- Must be established early in the system design process

- Should consider all aspects of operations including integration, test and launch through disposal

- Must include operational scenarios that are dynamic in nature, covering various modes and mode transitions with the key component being the inclusion of interactions with external interfaces

The first two items listed above that were taken from the NASA Systems Engineering Handbook are very important for the Preliminary LSP ConOps. Establishing the ConOps early in the design process is something that will require some proactive effort by LSP. The normal timeline for LSP to get involved is near the spacecraft CDR, which is not early the spacecraft design process. Therefore, this guidance will drive LSP into earlier involvement with our spacecraft customer. Considering all aspects of operations is also really critical for an LSP ConOps. LSP is the agency expertise when it comes to expendable launch vehicles, so LSP tends to focus on the launch vehicle. However, the spacecraft and other operational and external entities can be just as important as the launch vehicle in these operations.

The above professional references will serve as the foundation for the key attributes and characteristics of the LSP ConOps. However, before tailoring all of these inputs for the purposes of the LSP, the Launch Services Program and more specifically the integration function within LSP must be explained.

\section{A Summary of Launch Services}

NASA's Launch Services Program is often referred to as "Earth's Bridge to Space," because LSP procures and manages the launch services for all NASA and NASA-sponsored payloads that seek to utilize an Expendable Launch Vehicle (ELV) to reach space. The "NASAfacts" pamphlet (NASA, 2012) on LSP does a good job of concisely describing LSP's role:

"The Launch Services Program is responsible for NASA oversight of the launch service including launch vehicle engineering and manufacturing, launch operations and countdown management, and providing added quality and mission assurance in lieu of the requirement for the launch service provider to obtain a commercial launch license." 
The primary focus of the LSP Integration Engineer (IE) is the integration of the spacecraft with the launch vehicle. The LSP IE gets involved when reviewing the spacecraft Announcement of Opportunities and during spacecraft early mission feasibility studies and then again in support of some of the early spacecraft milestone reviews like SRR and PDR. Integration Engineering is also heavily involved with the development of the spacecraft Interface Requirements Document (IRD), where spacecraft to launch vehicle interface requirements are documented. The IRD is then used as an input into the launch services procurement process (which takes place in Phase $\mathrm{C}$ as shown in Figure 2). The spacecraft interface requirements from their IRD are tailored down into a concise set of interface requirements that form a significant portion of the Request For Proposal (RFP) that is released for potential launch vehicle contractors to bid against as part of the competitive launch service procurement. Once a launch vehicle has been selected the standard mission integration cycle begins. During mission integration LSP, the spacecraft project and the launch vehicle provider work together to start developing the mission ICD (which includes not only writing the interface requirements but the verification plans as well), performing the standard set of analyses that the launch vehicle provider runs to support the mission, planning for and executing spacecraft standalone tests that close out launch vehicle verifications and planning for and executing integrated operations. Figure 1 is a LSP Functional Architecture that has been tailored specifically for major functions that are supported by LSP Integration Engineering and shows in graphical form some of the activities just described.

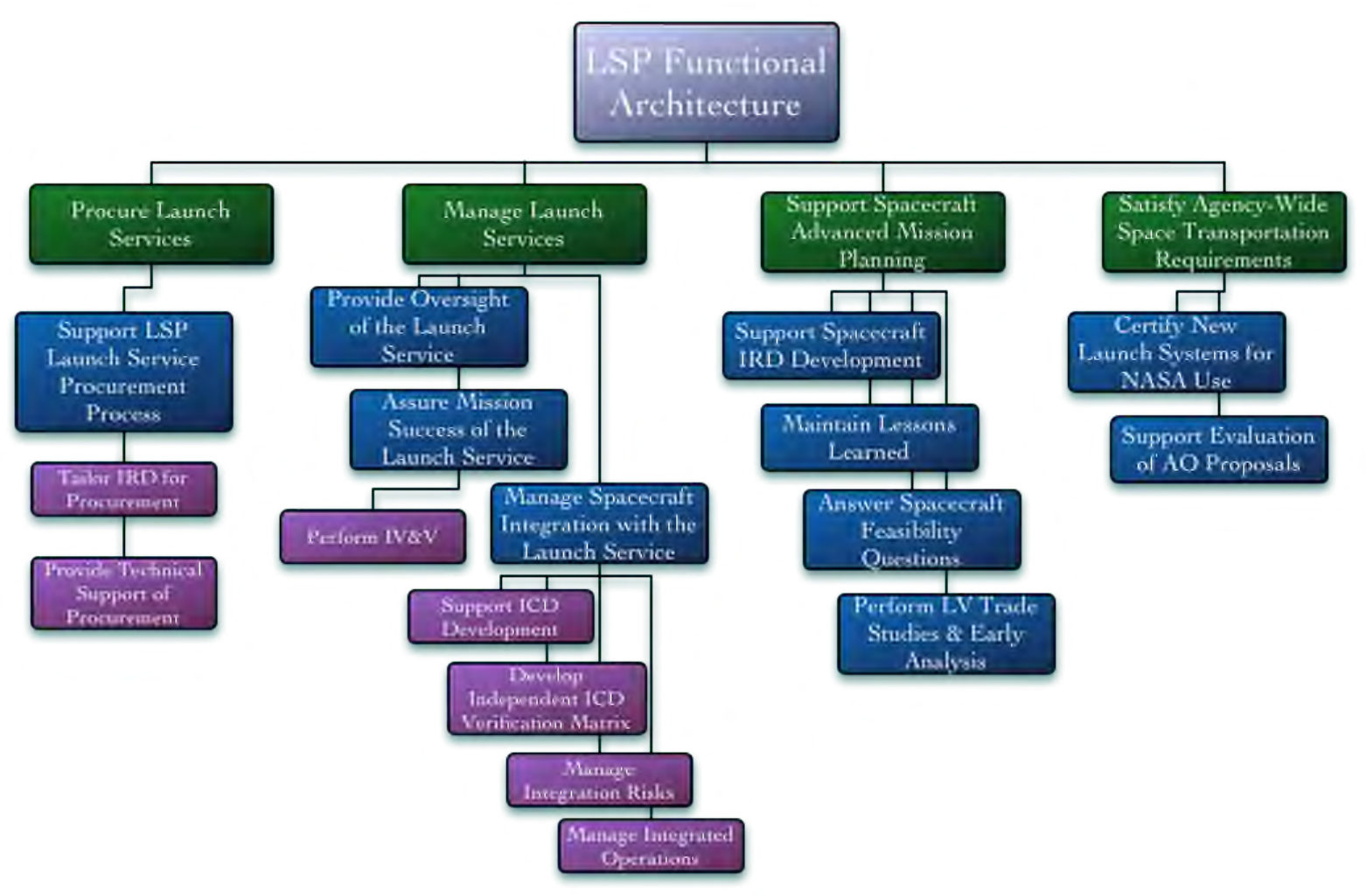

Figure 1. LSP IE Functional Architecture

LSP Integration Engineering is involved with four main functions: Procure Launch Services, Manage Launch Services, Support Spacecraft Advanced Mission Planning and Satisfy AgencyWide Space Transportation Requirements. The main function that has the most to gain from establishment of an LSP ConOps is the Manage Launch Services function, which is the activity where all the spacecraft integrated operations take place. However, the other three functions will benefit from a ConOps as well. The functional architecture of your organization is the 
foundation of the process of tailoring a ConOps and the role of this functional architecture will be explained in the next section of this paper.

\section{Scope of the LSP ConOps}

LSP has a need to develop two separate ConOps for integrated mission operations, one for very early mission planning that we are calling the "Preliminary ConOps" (before the launch service/launch vehicle is selected) and a second ConOps much later in the mission integration process when the mission Interface Control Document (ICD) is being developed (just prior to the start of integrated operations). Tailoring the Preliminary ConOps and documenting the process for this tailoring is the focus for this part. LSP has several groups that are involved with integrated operations, but this initial ConOps tailoring was mostly limited to the areas of responsibility of the LSP IE. The scope of LSP Preliminary ConOps is best explained with the use of a context diagram.

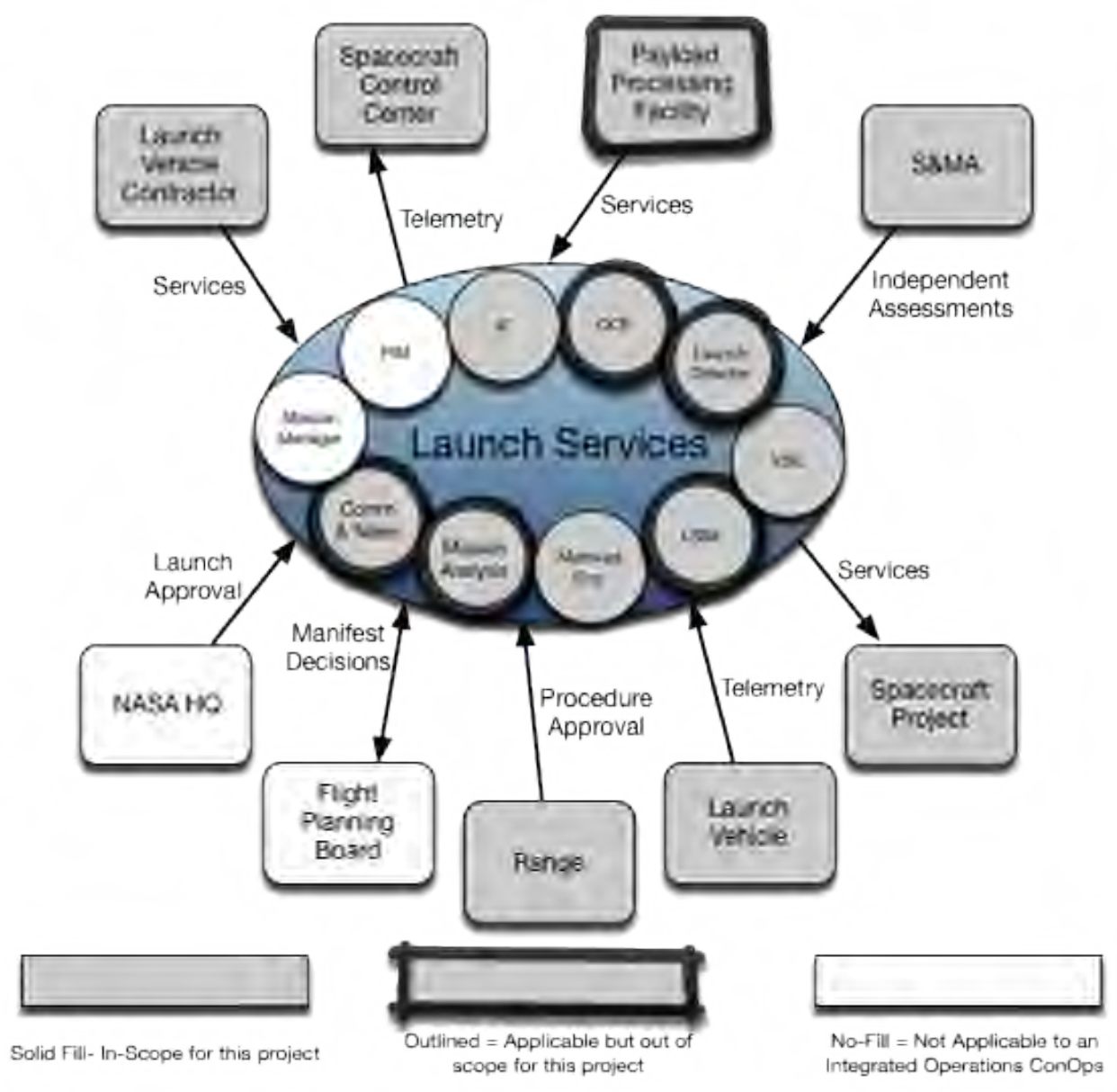

Figure 2. LSP Context Diagram

As illustrated in Figure 2, LSP interacts with many different entities. The small circles within the Launch Services oval are groups that are part of Launch Services (some are physically part of the Program and some are matrixed engineering support). Some of these entities do not come into play with respect to the LSP Integrated Operations ConOps, like the Flight Planning Board and NASA Headquarters (HQ). The prime interfaces for LSP are our spacecraft customer, the launch vehicle contractor and the payload processing facility (which is put on contract by the LSP Launch Site Integration Manager (LSIM) for our spacecraft customer). The LSIM, the Payload Processing Facility (PPF) and Communication and Telemetry are all very important 
aspects of the LSP ConOps but are not within the defined scope of this project. Formal coordination is required with the LSIM group within LSP and the time constraints of this project precluded having the formal reviews necessary to include their operations and scope with this first version of the ConOps. Communication and Telemetry is another very crucial service that LSP provides to our spacecraft customers that is within the scope of our ConOps but will have to be coordinated and included as future work.

\section{The Tailoring Process}

Tailoring the content for the LSP Preliminary ConOps was a seven-step process:

1. Identify Key Characteristics

2. Identify Key Functions

3. Identify Design Artifacts

4. Tailor Industry Standard ConOps Content

5. Identify Requirement Content

6. Identify Applicable Best Practices

7. Perform Full Content Mapping

These seven steps are described in detail below:

\section{Step 1: Identify Key Characteristics}

In the first section of this paper, key characteristics were identified from various industry standards and professional ConOps examples. The process for tailoring these characteristics was very simple and informal. Each key attribute was taken and modified in order to properly address the specific functions and culture that is inherent with how the Launch Services Program functions. These characteristics are applicable to both the early ConOps and the later ConOps developed once the launch vehicle has been selected. Each of the following tailored characteristics is immediately followed by rationale for why this characteristic is important to the LSP ConOps:

1. Will describe how the spacecraft and the LSP managed Launch Service will be operated during all integrated operations

Rationale: Each operation that includes some combination of spacecraft assets (hardware or personnel) and launch vehicle contractor assets (hardware or personnel) is considered an integrated operation. Operations can drive additional mission unique requirements that are not always apparent while developing an interface requirements document like an IRD or an ICD.

2. Will provide an overall picture of all the systems, facilities, processes and people that will be involved with integrated operations

Rationale: Graphical depictions of operations often reveal details and expectations that are difficult to convey in the form of written requirements. Graphical depictions of operations will act to supplement the spacecraft IRD, aid in the development of the launch vehicle contractor ICD and then be used to capture operational details that are not typically captured or appropriate for an ICD. 
3. Will include an overview of the mission's science objectives and the operations that are carried out by the spacecraft to meet those objectives

Rationale: Spacecraft science objectives are the main driver for the mission. Spacecraft operations are required in order to carry out the mission and meet the science objectives. Spacecraft operations, even though most of them occur after separation from the launch vehicle, can flow requirements down to the launch service and the launch vehicle hardware. A good example of this is with contamination control requirements that are driven by science goals for a sample return mission. Identifying spacecraft mission operations that are directly linked to science objectives early in the mission development cycle can reduce the likelihood of inadequately flowing spacecraft operational requirements down to the launch vehicle.

4. Will be written from the perspective of the spacecraft customer, who is the end user of the Launch Service

Rationale: A ConOps is first and foremost a communication tool. In order to effectively communicate operational needs and expectations between the spacecraft customer and the launch vehicle contractor and to ensure the customer needs are properly captured, the document should be written using terminology that is consistent with the spacecraft project.

\section{Will be utilized as a resource during the development of the ICD}

Rationale: Graphical representations of operations are informational rich than written interface requirements, and up until this point, written interface requirements have been the source material for launch vehicle ICDs (i.e. leveraging from the spacecraft project IRD and the launch vehicle contractor's ICD template). By supplementing the ICD development with an already established ConOps we are less likely to miss requirements or misinterpret them when creating the ICD.

6. Will be used to facilitate the capture of spacecraft customer expectations

Rationale: Operational details are not meant to be captured by an interface requirements document. Historically we have captured operational details and expectations in the form of operational working group telecons starting several weeks before planned integrated operations. Waiting until several weeks before integrated operations to discuss and compile operational details risks having large operational needs/requirements go unidentified.

7. Should consider all aspects of operations that use launch vehicle hardware, launch vehicle contractor services/support and personnel and any activity that involves the Launch Services Program (IV\&V, government furnished equipment, facilities and services). This should span all planned operations including integration, test and launch through disposal.

Rationale: Needs to encompass all operations that have the potential to drive additional launch vehicle support above and beyond the standard services called out in our NASA Launch Services (NLS) contract.

8. Will be launch vehicle agnostic

Rationale: The ConOps will be developed before the procurement of the launch service so that it can be used as a tool to ensure that all mission unique requirements (including operationally derived requirements) are identified before competing the launch service. 
Eventually the ConOps could also be used as an additional reference document provided along with the Request for Proposal (RFP) to the potential bidders for the launch service

\section{Step 2: Identify Key Functions}

For this step use your organization's functional architecture (see Figure 1) and identify each sub-function in that functional architecture that was applicable to integrated operations. A small red circle with a unique number was overlaid on top of each applicable function (this numbering scheme will be used in subsequent steps).

\section{Step 3: Identify Design Artifacts}

This step is all about identifying the types of integrated operation design artifacts that are available during the early phases of our mission integration for inclusion in the ConOps. The source of this information for Step 3 will vary depending on your specific type of operation. A good place to start is industry guidance documents if you do not have any specific design document references to utilize. For major spacecraft mission design milestone reviews NASA uses the NASA System Engineering Processes and Requirements (NPR 7123.1B), which lists all of the content expected to be part of each major spacecraft milestone review. Therefore, for Step 3 LSP was able to list all of the expected content from these reviews and then identify those applicable to integrated operations. Just as in Step 2 a unique number was assigned to each applicable design artifact for use in subsequent steps. Figure 3 shows a small section of the applicable spacecraft design artifact mapping that was done, with each artifact that was applicable shown in bold and marked with a unique reference number.

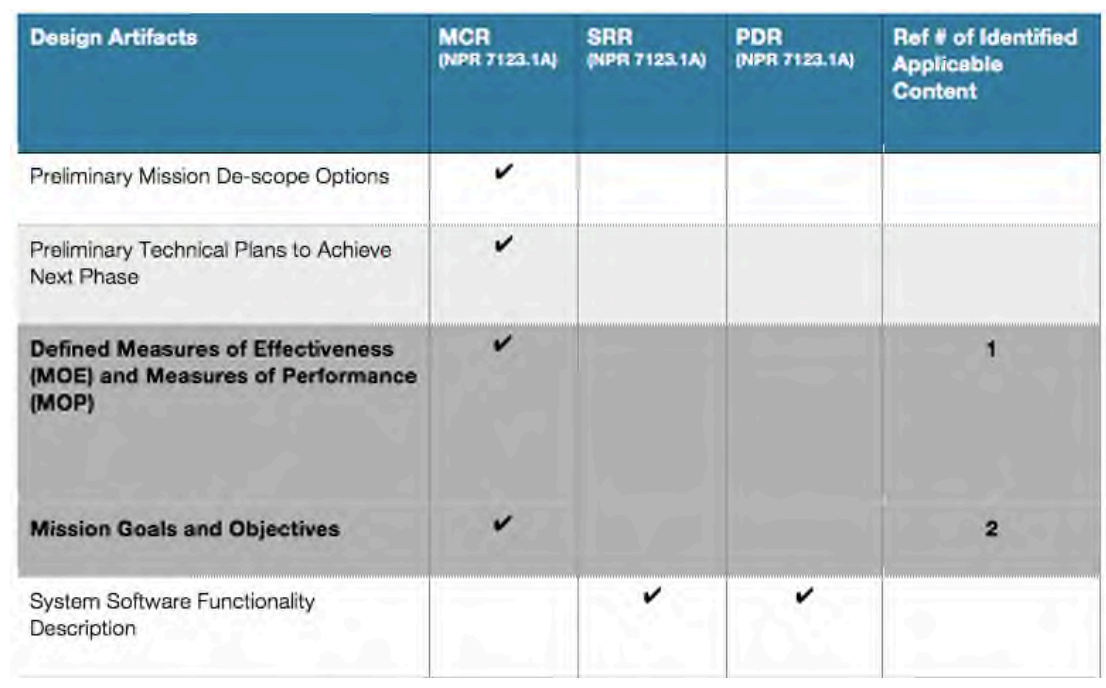

Figure 3. Example Applicable Design Artifacts Identification

\section{Step 4: Tailor Industry Standard ConOps Content}

There are a large number of example ConOps from which to choose, but only a few were selected for the basis of the content tailoring based on their recognition of being an "industry standard", their direct applicability due to a similar operating environment or because their structure was uniquely suited for the LSP ConOps need:

- IEEE Guide for Information Technology-System Definition-Concept of Operations (ConOps) Document (IEEE, 2007) 
- ANSI/AIAA G-043A-2012 Guide to the Preparation of Operational Concept Documents (ANSI, 2012)

- Operational Concept Description (OCD)-Space and Naval Warfare Systems Command (DI-IPSC-81430A, 2000)

- Federal Highway Administration - California Division: Concept of Operations Template (Federal, 2016)

The IEEE and ANSI standards are both well respected and commonly used across the industry as the foundation for many ConOps, so it seemed appropriate to include them as part of the tailoring inputs. The Operational Concept Description (OCD) document and the Federal Highway Administration (FHA) - California Division: Concept of Operations Template are both examples of having a structure that was different than other ConOps but well suited for to their specific ConOps purpose. What follows is a table summarizing the main section from each of these four documents with the last column of the table referencing back to the numbered Tailored LSP ConOps Characteristics listed in Section 5.1. Content from these four reference documents that relate heavily to the Tailored LSP ConOps Characteristics have been shaded and bolded in the table and will flow into the content structure for the LSP ConOps.

Each of the above industry ConOps examples was taken and their main content sections mapped into a single table. Each line in that table was grouped with similar content from other ConOps standards (if the other standards had related content). Once that was completed the last two columns of the table were created. The "LSP ConOps Content" column was the derived LSP content section name, which was based on an aggregation of all the related content names in that row but designed and name to match better with the type of content that applied to LSP integrated operations. The final column lists all of the applicable LSP ConOps characteristics identified in Step 1 that apply to the specific content of that line of the table. The resulting LSP ConOps Tailored Content is shown below in Figure 4.

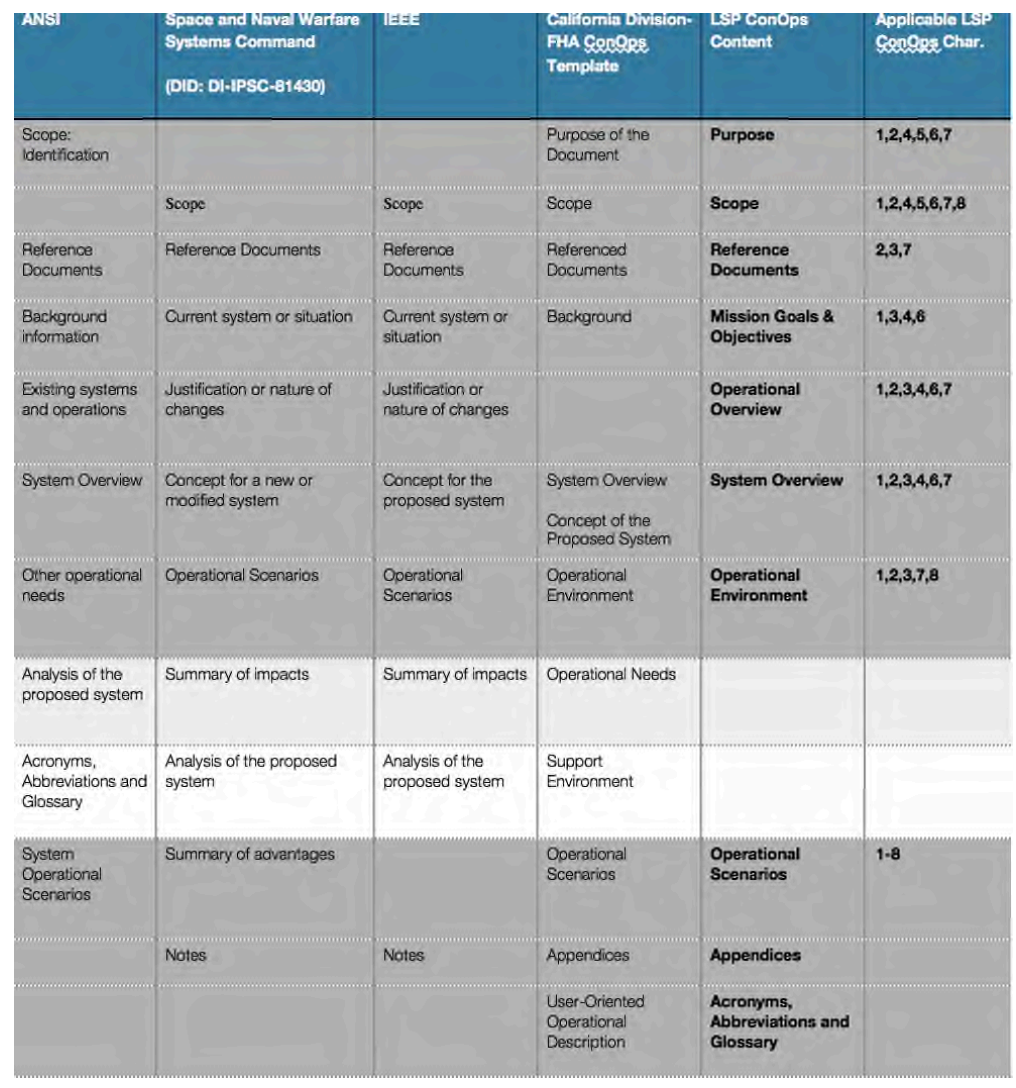

Figure 4. LSP ConOps Tailored Content 


\section{Step 5: Identify Requirement Content}

This step may or may not apply to your specific ConOps tailoring application. If the activity you are modeling has an applicable requirements document or documents, then all requirements that apply to integrated operations should be identified and categorized into high-level groupings. Assign each of these categories of requirements a unique number to be used in subsequent steps in the process. Table 1 below is the launch vehicle procurement requirement content that was identified as applicable to LSP integrated operations.

\begin{tabular}{|c|c|c|c|c|}
\hline $\begin{array}{c}\text { 1. Instrument Purge } \\
\text { Interface \& Ops }\end{array}$ & $\begin{array}{c}\text { 2. Spacecraft Fairing } \\
\text { Access Points/Ops }\end{array}$ & $\begin{array}{c}\text { 3. Electrical } \\
\text { Interfaces, timing of } \\
\text { connection and data } \\
\text { types }\end{array}$ & $\begin{array}{c}\text { 4. Separation } \\
\text { Indication }\end{array}$ & $\begin{array}{c}\text { 5. Launch Vehicle } \\
\text { Telemetry Ops }\end{array}$ \\
\hline $\begin{array}{c}\text { 6. Pre-Launch Env. } \\
\text { Control System Limits } \\
\text { and Ops }\end{array}$ & $\begin{array}{c}\text { 7. Mission Unique } \\
\text { Cooling Ops } \\
\text { Control Ops }\end{array}$ & $\begin{array}{c}\text { 8. Contamination } \\
\text { Protection Ops }\end{array}$ & $\begin{array}{c}\text { 9. Trajectory/Flight } \\
\text { Ops }\end{array}$ \\
\hline $\begin{array}{c}\text { 11. Ground Ops } \\
\text { 12. Env. Test Support }\end{array}$ & $\begin{array}{c}\text { 13. Propellant Offload } \\
\text { Ops }\end{array}$ & 14. Transport Ops & $\begin{array}{c}\text { 15. Payload } \\
\text { Processing Facility } \\
\text { Ops }\end{array}$ \\
\hline $\begin{array}{c}\text { 16. Mechanical } \\
\text { Interfaces Ops }\end{array}$ & $\begin{array}{c}\text { 17. Post-Separation } \\
\text { Ops }\end{array}$ & & & \\
\hline
\end{tabular}

Table 1. Typical LV Procurement Requirement Content

\section{Step 6: Identify Applicable Best Practices}

This is another step in the process that may or may not be applicable to your specific integrated operations. If your organization or professional sector has a handbook that documents best practices and lessons learned then it strongly encouraged that you include a step in your tailoring process to identify any applicable content or guidance from those resources for inclusion in your ConOps. Just as in the previous step, review any applicable resources and identify sections of content from those resources. Assign each of these categories of requirements a unique number to be used in subsequent steps in the process. Table 2 below is the NASA SE Handbook content that was identified as applicable to LSP integrated operations.

\begin{tabular}{|c|c|c|c|}
\hline \multicolumn{3}{|c|}{$\begin{array}{c}\text { 1. Description of the major phases (includes the following: Integration and test operations, Launch Operations, Science } \\
\text { Operations, Safe-Hold Operations, Anomaly Resolution and Maintenance Operations, Disposal Operations) }\end{array}$} \\
\hline 2. Operational Timelines & $\begin{array}{c}\text { 3. Operational Scenarios } \\
\text { and/or DRM }\end{array}$ & $\begin{array}{c}\text { 4. End-To-End } \\
\text { Communications Strategy }\end{array}$ & $\begin{array}{c}\text { 5. Integrated Logistics } \\
\text { Support (re-supply, } \\
\text { maintenance and assembly) }\end{array}$ \\
\hline 6. Critical Events & $\begin{array}{c}\text { 7. Command and Data } \\
\text { Architecture }\end{array}$ & 8. Operational Facilities & \\
\hline
\end{tabular}

Table 2. NASA SE Handbook Content

\section{Step 7: Perform Full Content Mapping}

This last remaining step for tailoring the ConOps content involves taking the tailored data and characteristics from steps 1-6 and mapping them into the proposed LSP ConOps table of contents from Figure 4. The end result is a structure from which the template of the Preliminary LSP ConOps can be created. The numbers in each of the columns in Figure 5 refer back to the reference numbers from the figures and tables from steps 1-6.

Figure 5 represents all of the mapped content for the Preliminary LSP ConOps. The main content sections listed in the first column of the table were created by taking the content from Figure 4 and consolidating that content down to a structure and sequence that made sense for how LSP provides services to our spacecraft customer. Those basic content types from Figure 
4 were then taken and compared against the following existing ConOps documents and NASA training materials and a common structure was created based on the author's judgment and background from working within LSP. It is highly recommended that several example ConOps from your particular industry or specialty be used as a model for this last step in the process. When it comes to a concept of operations there are a lot of good examples out there from which to pull, but it is important that the exact structure and content be scrutinized and tailored for the specific application. As an example, the three main sources used for determining the final table of contents for the Preliminary LSP ConOps were:

- $\quad$ James Webb Space Telescope Operations Concept Document (JWST, 2014)

- $\quad$ Space Vehicle Operators Concept of Operations (Space, 2004)

- $\quad$ NASA Space Systems Engineering ConOps Training Module (Scoping, 2016)

\begin{tabular}{|c|c|c|c|c|c|}
\hline $\begin{array}{l}\text { LSP Condps } \\
\text { Content }\end{array}$ & LSP Functions & $\begin{array}{l}\text { Spacecraft } \\
\text { Design Artifacts }\end{array}$ & $\begin{array}{l}\text { LV } \\
\text { Procurement } \\
\text { Requirements }\end{array}$ & $\begin{array}{l}\text { MASA SE } \\
\text { Handbook }\end{array}$ & $\begin{array}{l}\text { Tailored LSP } \\
\text { ConOps } \\
\text { Characteristice }\end{array}$ \\
\hline Purpose & & & & & $1,2,4,5,6,7$ \\
\hline Scope & & $1-\theta$ & & & $1,2,4,5,6,7,8$ \\
\hline $\begin{array}{l}\text { Ploferences } \\
\text { Documents }\end{array}$ & 7 & $1-\theta$ & & & $2,3,7$ \\
\hline $\begin{array}{l}\text { Mission Goals \& } \\
\text { Objectives }\end{array}$ & 7 & $2,3,4$ & & $3,6,7$ & $1,3,4,8$ \\
\hline $\begin{array}{l}\text { Operational } \\
\text { Oveview }\end{array}$ & 3,7 & $2,3,8$ & $1-17$ & $1-8$ & $1,2,3,4,6,7$ \\
\hline $\begin{array}{l}\text { System } \\
\text { Oveniow }\end{array}$ & 3,7 & $1,2,3,4,5,7,8,9$ & $1-17$ & & $1,2,3,4,6,7$ \\
\hline $\begin{array}{l}\text { Operational } \\
\text { Envirociment }\end{array}$ & $1,2,3,6,7$ & $3,4,7,8$ & $1-17$ & $1,3,5,8$ & $1,2,3,7,8$ \\
\hline $\begin{array}{l}\text { Operational } \\
\text { Scenarios }\end{array}$ & $1-7$ & $1,3,7,8$ & $1-17$ & $1,3,4,5,8$ & 1.8 \\
\hline \multicolumn{6}{|l|}{ Appendices } \\
\hline $\begin{array}{l}\text { Acronyms; } \\
\text { Abbrevistions } \\
\text { and Clossary }\end{array}$ & & & & & \\
\hline
\end{tabular}

Figure 5. Full LSP Content Mapping

\section{Configuration Management}

The ANSI/AIAA G-043A-2012 Guide to the Preparation of Operational Concept Documents (ANSI, 2012) recommends that the role of configuration management and change authority of a ConOps document be placed at the "lowest practical level." Since the LSP Integration Engineering group is establishing this LSP ConOps document, this group should also take responsibility for configuration management and change control. The LSP Mission Analysis Division already has a configuration management process in place for their analytical models using a SubVersion configuration management repository. LSP Integration Engineering will leverage from this existing process and capability to provide configuration management of both the Preliminary and Final LSP ConOps documents. 


\section{The Final Product and Future Work}

Figure 5 represents the final mapped content for the tailored Preliminary LSP ConOps, but this does not define the format for this content. Pictures, figures and diagrams should be heavily utilized in a concept of operations since a ConOps is not meant to be a verbose requirements document. The Mission Goal and Objectives, Operational Overview, System Overview, Operational Environment, and Operational Scenarios are expected to use visual representations wherever practical, while the opening sections of the ConOps like Purpose, Scope and Reference Documents will follow the more conventional written documentation form. Figure 6 below is an example of a FireSat ConOps diagram created for the Stevens Institute of Technology Cost Effective Space Mission Operations (SDOE 637) class (Cost, 2012) and then modified/annotated an example format for the Mission Objectives section.

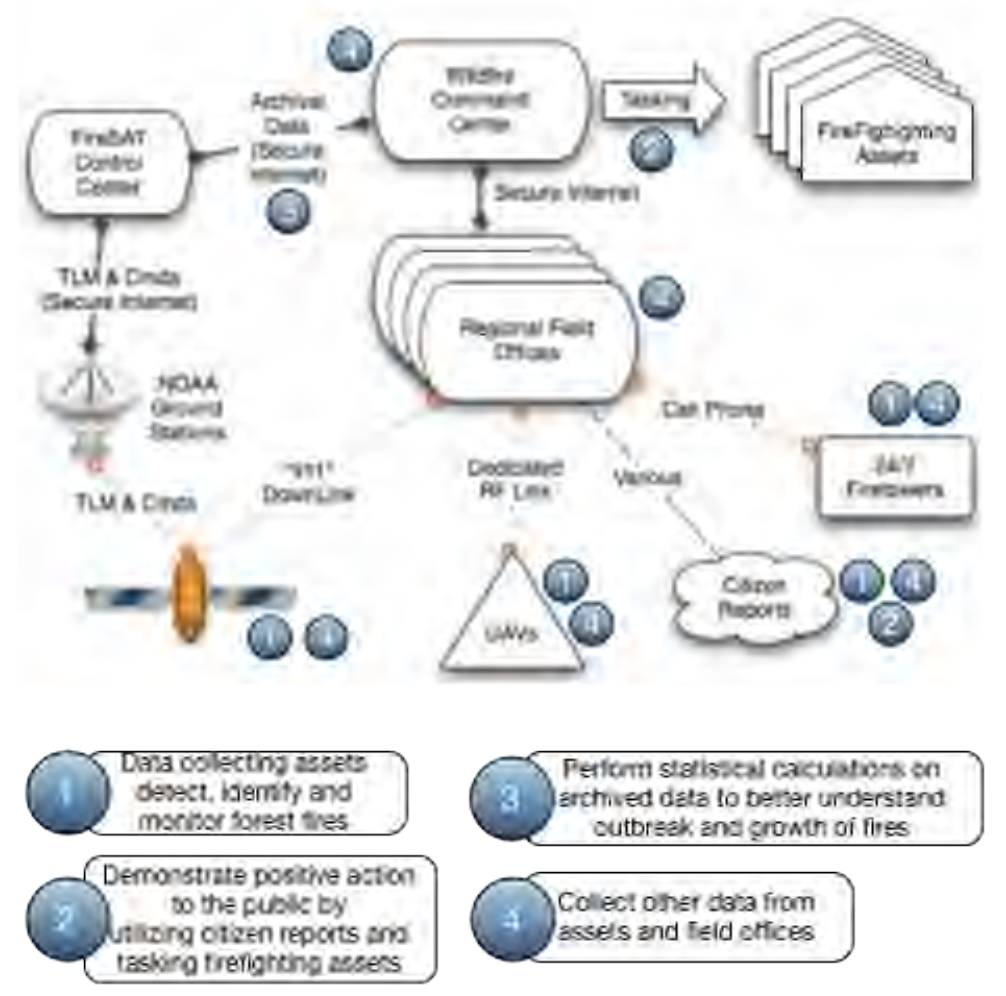

Figure 6. Example FireSat ConOps Objectives Diagram

The FireSat example figure above was used to show how an already existing figure (in this case a diagram in the paper materials for a Stevens Institute of Technology class - used with permission) was converted into a digital image, annotated and had a tabular set of descriptions added. Re-use of existing figures is highly recommended, as this will encourage images and figures to the greatest extent possible.

Most of the content in the Preliminary LSP ConOps is going to be the section called "Operational Scenarios." This is where details about each integrated operation will be documented. Since this particular version of the LSP ConOps is created before the launch service is selected (very early in the mission integration flow) there is not a lot of operational detail available. Therefore, the use of tabular data to document these early concepts for integrated operations is perfectly acceptable. Figure 7 below shows the format that was developed for the template document for the Preliminary LSP ConOps. If pictures, figures or graphics are available it is recommended that they be included at the very top of the table as part of the figure. 
A complete template document and corresponding instructions have been created for the Preliminary LSP ConOps and it can be found along with the original masters project work on the NASA Technical Reports Server (Owens, 2016).

\begin{tabular}{|l|l|}
\hline Operation Name & \\
\hline Start Date (L-I) & \\
\hline Duration & \\
\hline Facility Name \& Location & $\begin{array}{l}\text { Role/Tite: } \\
\text { Namec }\end{array}$ \\
\hline Lead Spacecraft Personnel & $\begin{array}{l}\text { Role/ritie: } \\
\text { Name: }\end{array}$ \\
\hline Lead Spacecraft Personnel & $\begin{array}{l}\text { Role/Title: } \\
\text { Name: }\end{array}$ \\
\hline Lead LV Porsonnel & \\
\hline Major Spaceoraft Components & \\
\hline Major Launch Vohicle Components & \\
\hline GFE & \\
\hline Inputs and Proceding Operations & \\
\hline Operational Objectives & \\
\hline Operational Environment/Restrictions & \\
\hline Timeline/Sequence & \\
\hline Spacecraft Procedure Name(s) & \\
\hline Launch Vohicle Procedure Name(s) & \\
\hline
\end{tabular}

Figure 7. Example Integrated Operations Summary Figure

The tailoring of ConOps content and the creation of the Preliminary LSP ConOps template was just the beginning of the process to start formally using a concept of operations with LSP missions. Formal collaboration is still required with the other operational groups within LSP before the Preliminary LSP ConOps template can be finalized and formalized with LSP Program Management. Additionally, more work is needed to define the process and mechanisms that will be used to allow both LSP and the spacecraft project to collaborate on the population of the Preliminary LSP ConOps template with mission data. A process for populating, base lining and updating the Preliminary ConOps will need to be established by LSP and an efficient mechanism for collaboration should also be put into place. The template for the Final LSP ConOps (which is developed later in the mission integration cycle) should also be developed. The most efficient way to create the Final LSP ConOps after the launch vehicle has been selected and in parallel with the mission ICD development is to use the Preliminary LSP ConOps template as the starting point for the structure of the Final LSP ConOps. Some iteration in format and content may be required in order to achieve the right balance of minimizing the effort required to support the population of these documents while at the same time maximizing the return on investment (which is the strengthening of the formal products like the IRD, reduced IRD for launch vehicle procurement, ICD and operational procedures and plans). 


\section{References}

"7123.1B NASA Systems Engineering Processes and Requirements." NODIS Library. NASA.gov, 18 Apr. 2013. Web. 06 Mar. 2016. <http://nodis3.gsfc.nasa.gov/displayDir.cfm?t=NPR>.

"ANSI/AIAA G-043A-2012 Guide to the Preparation of Operational Concept Documents - Freestd - American Nuclear Society Specification." ANSI/AIAA G-043A-2012Guide to the Preparation of Operational Concept Documents - Freestd - American Nuclear Society Specification. ANSI/AIAA. Web. 06 Feb. 2016.

"APPEL-LPSE Lifecycle, Process, and Systems Engineering." NASA APPEL PM\&SE Course. Florida, Kennedy Space Center. 2 May 2011. Reading. v02.01.04

Beck, Norm. "Developing a ConOps for LSP Missions." Personal interview. 22 Jan. 2016.

Cost Effective Space Mission Operations SDOE 637 Class Materials. Vol. 2. Hoboken: Stevens Institute of Technology, 2012. Print.

"DI-IPSC-81430A: Operational Concept Description (OCD)." FAA.gov. FAA, 10 Jan. 2000. Web. 06 Mar. 2016. <https://sowgen.faa.gov/dids/DI-IPSC-81430A.doc>.

"DOD Dictionary of Military and Associated Terms." DOD Dictionary of Military and Associated Terms. Jan. 2002. Web. 14 Feb. 2016. <http://www.dtic.mil/doctrine/dod_dictionary/>.

"Federal Highway Administration - California Division: Concept of Operations Template." California Division I Federal Highway Administration. Federal Highway Administration. Web. 06 Mar. 2016. $<$ https://www.fhwa.dot.gov/cadiv/segb/views/document/sections/section8/8_4_5.cfm\#top>.

"IEEE Guide for Information Technology - System Definition - Concept of Operations (ConOps) Document." (2007). Web. 6 Mar. 2016. <https://standards.ieee.org/findstds/standard/13621998.html>.

"JWST Mission Operations Concept Document." STCI.edu. NASA.gov, 14 July 2014. Web. 17 Mar. 2016. <http://www.stsci.edu/jwst/doc-archive/technical-reports/JWST-MOCD.pdf>.

Larson, Wiley J., Doug Kirkpatrick, Jerry J. Sellers, L. Dale Thomas, and Dinesh Verma, eds. Applied Space Systems Engineering. Boston, MA: McGraw-Hill Learning Solutions, 2009. Print.

NASA Systems Engineering Handbook. Washington, DC: National Aeronautics and Space Administration, 2007. Print.

"National Aeronautics and Space Administration - NASA." Web. 01 Mar. 2016. <http://www.nasa.gov/centers/kennedy/pdf/631039main_LSP_FACT_SHEET_onlinemarch15-12.pdf>.

Owens III, Clark V. "A Tailored Concept of Operations for NASA LSP Integrated Operations." (2016): n. pag. NASA Technical Reports Server (NTRS). Web. 24 Oct. 2016.

"Scoping \& Concept of OperationsScoping \& Concept of ..." NASA.gov. Web. 17 Mar. 2016. $<$ http://athena.ecs.csus.edu/ grandajj/ME296J/1. Lectures/5. Scope \& Conops Module/5.Scoping\&ConOps_Module_V1.0.pdf>.

"SPACE VEHICLE OPERATORS CONCEPT OF OPERATIONS : A Vision to Transform Ground and Launch Operations." FAA.gov. FAA, Oct. 2004. Web.

<https://www.faa.gov/about/office_org/headquarters_offices/ast/ media/Space_Vehicle_Operators_CONOPS_v18.pdf>.

Walden, David D. INCOSE Systems Engineering Handbook: A Guide for System Life Cycle Processes and Activities. Hoboken: Wiley, 2015. Print.

\section{Biography}


"Skip" Clark V. Owens III is a systems engineer in the Integration Engineering Branch of the Launch Services Program at NASA Kennedy Space Center. Mr. Owens graduated from Wichita State University with a B.S. in Aerospace Engineering and has a M.S in Space Systems Engineering from the Stevens Institute of Technology. Mr. Owens has experience working space mission design and operations from both a spacecraft and a launch vehicle perspective.

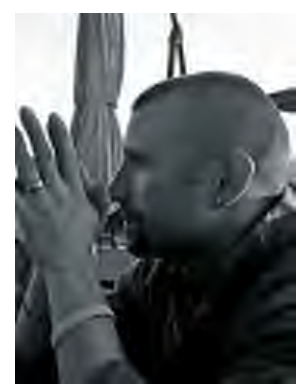

